\title{
Fermentation, Isolation, Structure, and antidiabetic activity of NFAT-133 produced by Streptomyces strain PM0324667
}

\author{
Asha A Kulkarni-Almeida1*, Manoja K Brahma', Prabhu Padmanabhan', Prabhu D Mishra', Rajashri R Parab, \\ Nitin V Gaikwad ${ }^{1}$, Chandni S Thakkar ${ }^{1}$, Pradipta Tokdar ${ }^{1}$, Prafull V Ranadive ${ }^{1}$, Amrutha S Nair ${ }^{1}$, Anagha A Damre ${ }^{1}$, \\ Umakant A Bahirat ${ }^{1}$, Nitin J Deshmukh', Lalit S Doshi ${ }^{1}$, Amol V Dixit ${ }^{1}$, Saji D George ${ }^{1}$, Ram A Vishwakarma ${ }^{2}$, \\ Kumar VS Nemmani ${ }^{1}$ and Girish B Mahajan ${ }^{1 *}$
}

\begin{abstract}
Type-2 diabetes is mediated by defects in either insulin secretion or insulin action. In an effort to identify extracts that may stimulate glucose uptake, similar to insulin, a high throughput-screening assay for measuring glucose uptake in skeletal muscle cells was established. During the screening studies to discover novel antidiabetic compounds from microbial resources a Streptomyces strain PM0324667 (MTCC 5543, the Strain accession number at Institute of Microbial Technology, Chandigarh, India), an isolate from arid soil was identified which expressed a secondary metabolite that induced glucose uptake in L6 skeletal muscle cells. By employing bioactivity guided fractionation techniques, a tri-substituted simple aromatic compound with anti-diabetic potential was isolated. It was characterized based on MS and 2D NMR spectral data and identified as NFAT-133 which is a known immunosuppressive agent that inhibits NFAT-dependent transcription in vitro. Our investigations revealed the antidiabetic potential of NFAT-133. The compound induced glucose uptake in differentiated L6 myotubes with an $\mathrm{EC}_{50}$ of $6.3 \pm 1.8 \mu \mathrm{M}$ without activating the peroxisome proliferator-activated receptor- $\gamma$. Further, NFAT-133 was also efficacious in vivo in diabetic animals and reduced systemic glucose levels. Thus it is a potential lead compound which can be considered for development as a therapeutic for the treatment of type-2 diabetes. We have reported herewith the isolation of the producer microbe, fermentation, purification, in vitro, and in vivo antidiabetic activity of the compound.
\end{abstract}

Keywords: NFAT-133, Streptomyces sp., Antidiabetic, Actinomycetes

\section{Background}

In 2010, the global prevalence of diabetes was estimated to have reached 285 million and it is predicted to reach 438 million in 2030. Available agents provide imperfect control of the disease, and the medical need for better therapies is widely recognized (Norman 2010). About $90 \%$ to $95 \%$ of patients have non-insulin dependent diabetes mellitus (NIDDM) or type-2 diabetes and the standard therapy for the treatment of NIDDM has its own limitations (Mark 1997). Diet, oral hypoglycaemic drugs and insulin are the standard modes of treatment.

\footnotetext{
* Correspondence: asha.almeida@piramal.com; girish.mahajan@piramal.com 'Piramal Life Sciences Limited, 1-Nirlon Complex, Off Western Express Highway, Goregaon (East), Mumbai-400063, Maharashtra State, India Full list of author information is available at the end of the article
}

However they are unable to achieve relief from diabetes. This leads to acute and chronic complications. Hence major efforts have been directed towards development of oral hypoglycaemic drugs, to identify both novel insulin secretagogues and compounds able to enhance insulin action in target tissues.

High throughput screening of natural product libraries had previously been attempted by us as an approach towards identifying novel scaffolds with potent biological activity (Kulkarni-Almeida et al. 2008). Several pharmaceutical industries use this approach to investigate natural product based library collections (Quinn et al. 2002). A major segment of these biota collections were represented by microbial cultures. Among the microbial resources actinomycetes have been proven to be a 
rewarding source of antidiabetic compounds. Acarbose, voglibose, valienamine, adiposin- 1 , and trestatin-B were reported from Actinoplanes utahensis (Schmidit et al. 1977), Streptomyces hygroscopicus-limoneus (De Melo et al. 2006; Kameda et al. 1980), S. calvus (Mahmud 2003; Truscheit et al. 1981), and S. dimorphogenes (Yokose et al. 1983; Yokose et al. 1984) respectively. Acarbose is an oral alpha-glucosidase and alpha-amylase inhibitor that was first launched by Bayer in Switzerland in 1989 for the oral treatment of type-2 diabetes mellitus (Schmidit et al. 1977). Voglibose is an alpha-glucosidase inhibitor used for lowering post-prandial blood glucose levels in people with diabetes mellitus. It is produced and marketed in India by trade name Volix ${ }^{\circledR}$ and $\operatorname{Vocarb}^{\circledR}(\mathrm{De}$ Melo et al. 2006). Valielamine, a precursor of voglibose and a new aminocyclitol were isolated from the fermentation broth of Streptomyces hygroscopicus subspecies limoneus. It has more potent $\alpha$-glucosidase inhibitory activity against porcine intestinal sucrase, maltase and isomaltase than valienamine, validamine and hydroxylvalidamine which were reported as building blocks of validamycins and microbial oligosaccharide $\alpha$-glucosidase inhibitors (Kameda et al. 1984; Xu et al. 2009).

One of the hallmarks of type- 2 diabetes is decreased sensitivity of cells to insulin. Our approach was to explore microbial collections for extracts with anti-diabetic metabolites that stimulate glucose uptake in skeletal muscle cells. Using this strategy we have previously identified plant extracts Aegle marmelos and Syzygium cumini which stimulate glucose uptake activity in L6 myotubes. This activity was mediated by activation of glucose uptake by glucose transporter 4 (GLUT4), peroxisome proliferator activator receptor gamma (PPAR- $\gamma$ ) and phosphatidylinositol 3' kinase (PI3K), (Anandharajan et al. 2006). Similarly, (Jung et al. (2006)) showed that Ganoderma lucidum extract stimulates glucose uptake activity in skeletal muscles by activating the regulatory molecules PI3-kinase and AMP activated protein kinase (AMPK). We explored the microbial metabolite extract library in search of compounds that enhance glucose uptake in skeletal muscle cells in presence of insulin. Upon insulin treatment of skeletal muscles, the insulin receptor is phosphorylated which activates a signal transduction pathway leading to increased translocation and GLUT4 (Yonemitsu et al. 2001). These features of L6 myotubes are critical since GLUT4 is responsible for insulin-dependent glucose uptake in the mature differentiated skeletal muscle cell.

High throughput screening of diverse microbial metabolite extract library was conducted for detecting glucose uptake inducers in rat skeletal muscle cells. The extract library is prepared from diverse microbes isolated from variety of ecological units in India. 880 extracts representing Actinomycetes strains yielded eight actives. These could stimulate glucose uptake in differentiated skeletal muscle cells. The extract of an actinomycetes strain PM0324667 of the genera Streptomyces showed reproducible glucose uptake activity through several refermentation generations. Using fermented broth of this strain, bioactivity guided fractionation was conducted to isolate the active principle. We isolated the compound NFAT-133, which was earlier, reported as an immunosuppressive agent. This compound induced significant glucose uptake in rat skeletal muscle in presence of insulin. The activity was possibly mediated through a PPAR- $\gamma$ independent mechanism. Further, the compound showed a significant reduction in plasma glucose and plasma insulin levels in diabetic $(d b / d b)$ mice as compared to vehicle treated animals. In this paper, we report the antidiabetic activity of NFAT133 along with isolation of its producer microorganism, identification, fermentation, and structure elucidation.

\section{Materials and methods}

\section{Isolation of Streptomyces strain PM0324667}

The Streptomyces strain PM0324667 was isolated from a sandy soil sample collected from Jaipur in Rajasthan, India. The soil was suspended in demineralised water $(10 \% \mathrm{w} / \mathrm{v})$ and heated at $55^{\circ} \mathrm{C}$ for 6 minutes. $100 \mu \mathrm{l}$ of the suspension was spread on CSPYME agar consisting of casein $(0.1 \%)$, corn starch $(1.0 \%), \mathrm{K}_{2} \mathrm{HPO}_{4},(0.05 \%)$, peptone $(0.1 \%)$, yeast extract $(0.1 \%)$, malt extract $(1.0 \%)$, agar agar $(1.5 \%)$, hydroxylamine $(0.01 \%)$ and amphotericin-B $(0.002 \%)$ with initial $\mathrm{pH}$ value of 7.0 . The medium plates were incubated at $30^{\circ} \mathrm{C}$ for seven days. The colonies were transferred onto agarified ISP2 medium. ISP2 medium consisted of malt extract $(1.0 \%)$, glucose $(0.4 \%)$, yeast extract $(0.4 \%)$ and agar agar $(1.6 \%)$ with initial $\mathrm{pH}$ value of 7.0. The medium slants were incubated at $30^{\circ} \mathrm{C}$ for 7 days. Typical colonies of streptomycetes, with rough surface and chalky white or gray in color were picked-up on ISP2 agar plates. 47 colonies were isolated and purified from the arid soil sample. All 47 cultures from arid soils were screened in the in vitro antidiabetic assay. Streptomyces strain PM0324667 was one these 47 which showed consistent and reproducible antidiabetic activity.

\section{Taxonomy}

Microscopic and macroscopic features of the strain PM0324667 were examined by the classical microbiological techniques. Total DNA sample of the strain was prepared as reported (Arun et al. 2005). The $16 \mathrm{~S}$ ribosomal RNA gene (16S rRNA) was amplified by polymerase chain reaction (PCR) using genomic DNA and universal primers 243F (5'-GGA TGA GCC CGC GGC CTA-3') forward primer and 1385R (5'-CGG TGT GTA CAA GGC CC-3') - reverse primer and sequenced (Arun et 
al. 2005). A homology search for the most nearest sequences was performed using the BLAST algorithm on the GenBank/EMBL/DDBJ/PDB.

\section{Production of NFAT-133 by Streptomyces strain PM0324667}

Streptomyces strain PM0324667 (MTCC 5543) from the ISP2 medium slant was inoculated into seed medium; 274-(1) consisting of glucose (1.5\%), corn steep liquor $(0.5 \%)$, peptone $(0.75 \%)$, yeast extract $(0.75 \%)$, calcium carbonate $(0.2 \%)$ and sodium chloride $(0.5 \%)$ with initial $\mathrm{pH}$ value of 7.0. The culture was incubated on a rotary shaker $[240$ revolutions per minute $(\mathrm{rpm})]$ at $30^{\circ} \mathrm{C}\left( \pm 1^{\circ}\right.$ C) for three days. $5 \mathrm{ml}$ of this seed was inoculated into $100 \mathrm{ml}$ fermentation medium; 5189M consisting of malt extract $(2.0 \%)$, yeast extract $(0.2 \%)$, glucose $(1.0 \%)$ and $\left(\mathrm{NH}_{4}\right)_{2} \mathrm{HPO}_{4},(0.005 \%)$ with initial $\mathrm{pH}$ value of 6.0 . The fermentation was carried out on a rotary shaker (240 $\mathrm{rpm})$ at $30^{\circ} \mathrm{C}\left( \pm 1^{\circ} \mathrm{C}\right)$ for three days.

\section{Extraction and isolation}

The fermented broth was extracted with methanol (1:1, $\mathrm{v} / \mathrm{v}$ ) and it was stirred for 60 minutes and filtered through a coarse filter paper. The filtrate was concentrated using vacuum concentrator. The aqueous concentrate was passed through $10 \%(\mathrm{v} / \mathrm{v})$ bed volume of Diaion ${ }^{\circledR}$ HP20 (SUPELCO) resin at the rate of $1 \mathrm{~L} / \mathrm{h}$. The adsorbent on the resin was eluted with $80 \%$ methanol after water wash. The methanolic extract was dissolved in demineralized water to get concentration of 75 $\mathrm{mg} / \mathrm{ml} .100 \mathrm{ml}$ of this aqueous solution was partitioned with $100 \mathrm{ml}$ ethyl acetate (EA) five times. The EA extracts were pooled together and dried on vacuum concentrator.

The EA concentrate was dry charged to CombiFlash chromatography instrument with pre packed Redisep silica gel column (10 g). The column was sequentially eluted with chloroform and methanol mixture (5-20\% methanol) and the fractions monitored by thin layer chromatography (TLC). Similar fractions were pooled to get three samples namely; Fraction-1, Fraction-2 and Fraction-3. These samples along with crude extract of EA were screened for glucose uptake activity. The active Fraction-1 was subjected to reverse phase silica (C-18) cartridge, strata ${ }^{\mathrm{TM}}$ from Phenomenex and eluted with water: acetonitrile mixture in gradient mode. The pure compound was recovered from the $20 \%$ acetonitrile eluate, by evaporating acetonitrile and water using a high vacuum concentrator.

\section{Structure elucidation}

HPLC was performed using a Lichrosphere RP-18 column $(125 \times 4 \mathrm{~mm})$ in a Shimadzu LC-2010CHT Liquid Chromatograph. The final purification was done on
Waters PrepLC 4000 System. Solvents used for reversephase were of HPLC grade and normal-phase column chromatography was performed with demineralized commercial-grade solvents. Silica gel $\left(\mathrm{SiO}_{2} ; 200-300\right.$ mesh) was used for CC and GF254 (30-40 mm) TLC plates were procured from Merck. An NMR spectrum of the compound was recorded in $\mathrm{CDCl}_{3}$ on Bruker 300 $\mathrm{MHz}$ spectrometer with TMS as the internal standard. Chemical shift $\delta$ values were expressed in ppm, and coupling constant J in Hz. ESI LC-MS was recorded on Bruker Daltonics. CombiFlash ${ }^{\circledR} \mathrm{Sq} 16 \times$ Teledyne Technologies Company ISCO attached with UV/VIS detector was used for Flash chromatography, using RediSep ${ }^{\circledR}$ Flash Column silica $12 \mathrm{~g}$ Teledyne ISCO.

\section{Large scale fermentation}

A well-sporulated seven days old slant culture was inoculated into $200 \mathrm{ml}$ of seed medium consisting of glucose $(1.5 \%)$, corn steep liquor $(0.5 \%)$, peptone $(0.75 \%)$, yeast extract $(0.75 \%)$, calcium carbonate $(0.2 \%)$, and sodium chloride $(0.5 \%)$ in demineralized water with an initial $\mathrm{pH}$ value of 6.5-7.0 in $1 \mathrm{~L}$ erlenmeyer flasks. All the flasks were incubated on a rotary shaker for 3 days at $230-250 \mathrm{rpm}$ at $30^{\circ} \mathrm{C}\left( \pm 1^{\circ} \mathrm{C}\right) .2 .5 \mathrm{~L}$ seed was transferred to $150 \mathrm{~L}$ fermentor (B. Braun Melsungen AG) containing $100 \mathrm{~L}$ production medium consisting of malt extract $(2.0 \%)$, yeast extract $(2.0 \%)$, glucose $(1.0 \%)$, di-ammonium hydrogen phosphate $(0.005 \%)$ in demineralized water with initial $\mathrm{pH}$ value of 6.0 and fermented with the following parameters: aeration $0.5 \mathrm{vvm}$, temperature $30^{\circ} \mathrm{C}\left( \pm 1^{\circ} \mathrm{C}\right)$, agitation $100 \mathrm{rpm} .20 \%$ dextrose solution was fed at $24 \mathrm{~h}$ of the fermentation cycle at $5 \%$ $(\mathrm{v} / \mathrm{v})$ and the batch was harvested at $48 \mathrm{~h}$. The whole broth was extracted with equal volume of ethyl acetate (EA). The EA extract was used for isolation of the compound NFAT-133.

\section{Determination of in vitro activity Cell lines and Reagents}

The cell lines, media and reagents used in the assay are namely; alpha-MEM (Bioconcept), fetal bovine serum (Gibco), penicillin-streptomycin solution (Sigma), ${ }^{14} \mathrm{C}-2-$ deoxyglucose (GE Healthcare, UK)), 2-deoxyglucose (Sigma Aldrich, St. Louis, MO, USA), KRPH buffer (pH.7.4), Microscint PS (Perkin Elmer, USA), 96-well plates (Nunc), L6 rat skeletal muscle cells (CRL1458, ATCC, USA), human recombinant insulin (Sigma, St. Louis, MO, USA), rosiglitazone (synthesized in house).

\section{Assay Procedure}

The metabolite extract library samples were screened for the ability to induce glucose uptake in insulin stimulated differentiated L6 myotubes. The L6 rat skeletal muscle cells were seeded into 96 well cell culture plates in complete medium $(\alpha-$ MEM $+10 \%$ fetal bovine serum $+1 \%$ 
penicillin-streptomycin solution) and maintained at 5\% carbon dioxide $\left(\mathrm{CO}_{2}\right)$ atmosphere. After $48 \mathrm{~h}$, the medium was switched to $\alpha$-MEM with $2 \%(v / v)$ fetal bovine serum (FBS) in order to initiate differentiation. Media change was ensured every $48 \mathrm{~h}$. Compound treatment was conducted once the myoblasts differentiated to form myotubes. The differentiated and fused myotubes were starved in serum free $\alpha$-MEM for $4 \mathrm{~h}$, treated with samples and further incubated for $24 \mathrm{~h}$. Following treatment and incubation, the cells were sensitized with insulin (200 nM) and incubated for 25 minutes. Radioactive glucose pulsing was done at $0.06 \mu \mathrm{Ci} / \mathrm{ml}$ for 10 minutes. The reaction was terminated with cold KRPH buffer. The cell-associated radioactivity was determined by lysing the cells with Microscint PSTM followed by liquid scintillation counting (Huang et al. 2002). The assay was performed in triplicate.

For all experiments, the L6 myoblasts obtained from ATCC were used only up to passage seven and were utilized within two months post revival of a new vial.

\section{PPAR- $\gamma$ luciferase assay}

PPAR- $\gamma$ activation is one of the key mechanisms involved in glucose uptake. To determine if NFAT-133 was exerting its effects by activation of PPAR- $\gamma$, a luciferase assay was performed using the expression vector for human PPAR- $\gamma$ and the PPRE-tk-LUC reporter plasmid. CV1 cells were seeded onto 24 well plates and transient transfections were conducted after over-night incubation using lipofectamine (Invitrogen, CA, USA). Five hours after transfection, the cells were treated with each compound concentration for an additional $24 \mathrm{~h}$, and the luciferase assay (Promega) was performed according to the manufacture's protocol. Luminescence was measured using the Safire 2 reader. Transactivation of human PPAR- $\gamma$ by $1 \mu \mathrm{M}$ rosiglitazone is considered as $100 \%$ activation and hence data for NFAT-133 is calculated in comparison to rosiglitazone which was used as a positive control in the assay. The entire assay was performed in triplicates.

\section{Determination of in vivo activity Animals}

Male $d b / d b$ mice (7-9 weeks of age) were housed in individually ventilated cages at room temperature of $22^{\circ}$ $\mathrm{C} \pm 2{ }^{\circ} \mathrm{C}$, humidity at $55 \pm 5 \%$, with a $12: 12$-h light: dark cycle and throughout the study period had access to water and standard chow ad libitum. The guidelines of the Committee for the Purpose of Control and Supervision of Experiments on Animals, Government of India, were followed and the in-house animal ethics committee approved all experimental procedures.

\section{Biological Activity}

Male $d b / d b$ mice were divided into three groups of 10 animals each with similar body weight and plasma glucose (mean \pm S.E.M.) levels. Mice were treated with $0.5 \%$ carboxy methyl cellulose (CMC), rosiglitazone (5 mg/kg, p.o.), or NFAT-133 (100 mg/kg, i.p.) twice daily for 10 days. Body weight was measured daily. On day 10, one hour after the last dose, mice were fasted for four hours so as to minimize the variability between the animals. Blood was collected from the fasted mice, plasma was separated by centrifugation (6000 g at $4^{\circ} \mathrm{C}$ for 7 minutes) and glucose was estimated using a biochemistry auto analyzer (Hitachi Science Systems Limited, Ibaraki, Japan). A small aliquot of separated plasma was stored at $-20^{\circ} \mathrm{C}$ for estimation of insulin using an ELISA assay kit (Linco Research). Immediately after blood sample collection, mice were sacrificed, livers excised and weighed. The data was reproducible in two independent experiments.

\section{Statistical analysis}

All the results are expressed as Mean \pm S.E.M. Statistical analysis was done using GraphPad Prism 4 (version 4.03, GraphPad Software, Inc., CA, USA). For comparison between means of more than two groups one-way analysis of variance (ANOVA) followed by Dunnett's posthoc analysis was employed.

\section{Results}

Taxonomy of the Streptomyces strain PM0324667

The morphological characteristics of the culture Streptomyces strain PM0324667 on ISP2 agar were observed. The colonies had a rough surface, marginal areas divided into radial and concentric sections, dry, burst substrate mycelia with profound aerial mycelia, grayish sporulation, convoluted appearance, slightly yellowish diffusible pigment diffusing into the medium to give a buff yellow colour. The partial 16S rRNA gene sequence of the Streptomyces strain PM0324667 has been deposited at NCBI and allocated accession \# JF810673. This strain showed high similarity in $16 \mathrm{~S}$ rRNA gene sequence value with Streptomyces pactum; accession no. EF654095.1 (884/899, 98\%). Moreover it showed striking similarity $(884 / 894,98 \%)$ to Streptomyces parvisporogenes; accession numbers AB184375.1 and GU350508.1. The full phylogeny tree and blast results are shown in Figure 1 We found that our culture isolate bears closer resemblance to $S$. parvisporogenes as the sequence JF810673 has 98\% similarity with the two sequences of S. parvisporogenes (Accession numbers: AB184375.1 and GU350508.1). These phenotypic and genotypic properties suggest that the strain PM0324667 belongs to the genus Streptomyces. The strain is deposited and preserved at Institute of Microbial Technology, Chandigarh, India (Council of Scientific and Industrial Research, CSIR) under accession number Streptomyces sp. MTCC 5543. 


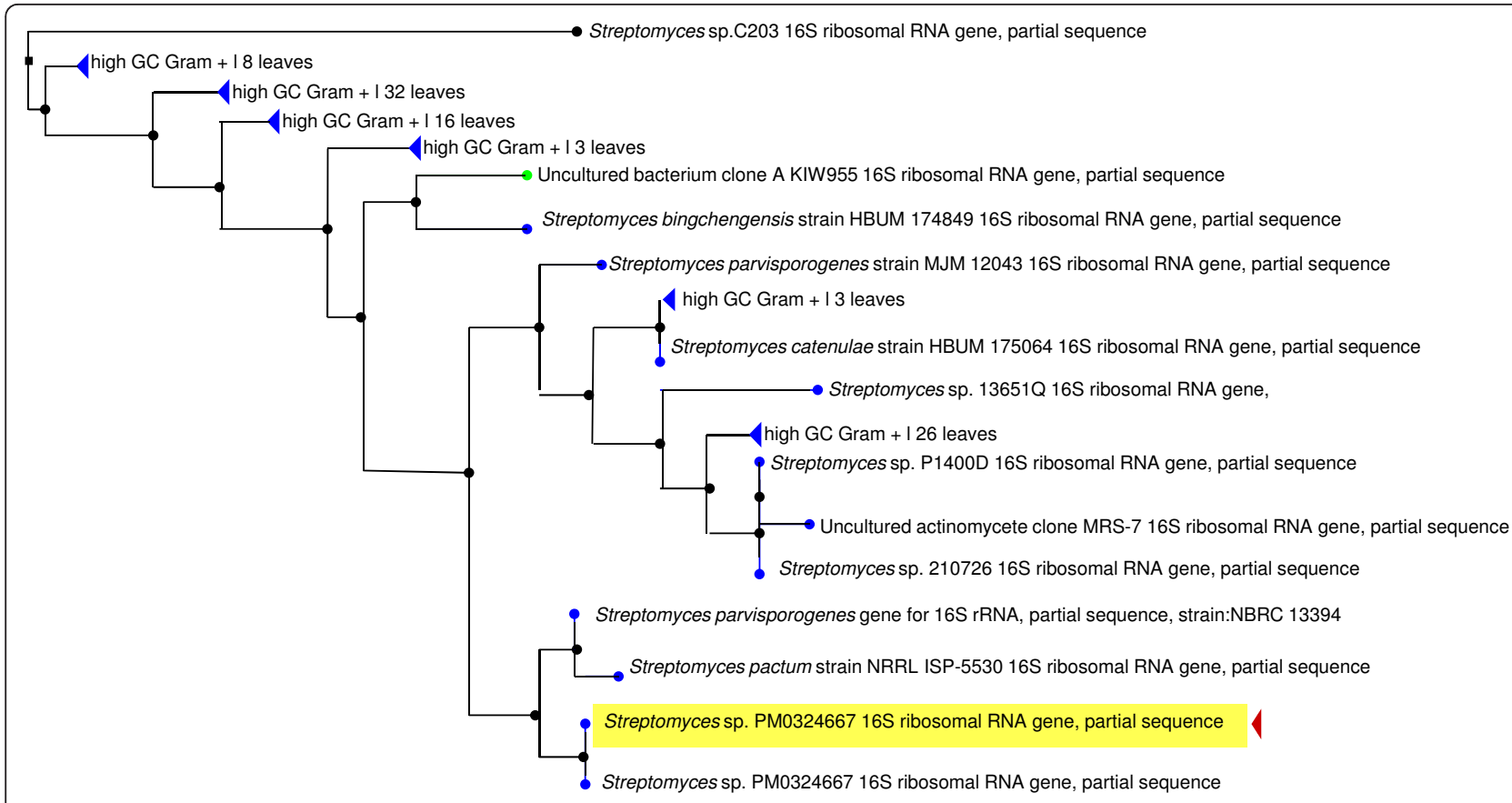

Figure 1 Phylogeny Tree view for query ID: JF810673, the partial 16S rRNA gene sequence from the of Streptomyces strain PM034667.

Effect of the ethyl acetate extract of PM0324667 on glucose uptake in differentiated skeletal muscle cells Insulin resistance in skeletal muscle cells is known to play a pivotal role in the development of diabetes. So we established a high throughput screen using L6 differentiated muscle cells as a model for evaluating the potency of natural product extracts in inducing glucose uptake. High throughput screening of the 20,000 microbial extracts library was conducted. Among the actives the extract from PM0324667 showed a 4-fold increase in glucose uptake activity as compared to control. It induced glucose uptake in differentiated L6 muscle cells in presence of $25 \mathrm{mM}$ glucose and $200 \mathrm{nM}$ insulin. The extract showed consistent and reproducible increase in glucose uptake activity at $3 \mu \mathrm{g} / \mathrm{ml}$ (Figure 2: Where glucose uptake in L6 myotubes exposed to vehicle $(0.5 \%$ DMSO), glucose uptake in presence of $30 \mu \mathrm{M}$ rosiglitazone; glucose uptake in presence of $3 \mu \mathrm{g} / \mathrm{ml}$ of the extract of PM034667) when subjected to several refermentation cycles. This effect was comparable to the effect of rosiglitazone at $30 \mu \mathrm{M}$ (approximately equal to $10.75 \mu \mathrm{g} / \mathrm{ml}$ ) in the same experiment.

\section{Isolation and characterization of NFAT-133}

As described in the experimental section, the EA extract of the whole fermentation broth was subjected to bioactivity-guided fractionation to identify the active principle responsible for the glucose uptake activity in PM034667. Three samples based on their fractional similarity were evaluated in the biological assay viz.,
$1111 / 38 / 1,2$ and 3 . These samples along with the crude $1111 / 27$ were screened for glucose uptake activity in differentiated skeletal muscle cells. Since bioactivity similar to that of rosiglitazone was observed to be residing in a single fraction $1111 / 38 / 1$, the same fraction was taken up for further isolation of the active principle (Table 1).

NFAT-133 was isolated by fermentation of the Streptomyces culture PM0324667 using optimized fermentation media and conditions as described in the experimental section. The biological activity coincided with the profile on a LC-ESI positive ion mass spectrum which showed a distinct peak $\mathrm{m} / \mathrm{z}$ at $299[\mathrm{M}+\mathrm{Na}]^{+}$ suggesting a molecular weight of the compound was 276 (Additional file 1). The compound was a pale yellow viscous oil with a UV absorption maxima of $212 \mathrm{~nm}$, and molecular formula; $\mathrm{C}_{17} \mathrm{H}_{24} \mathrm{O}_{3}$.

$\mathrm{A}^{13} \mathrm{C}$ NMR spectra (Table 2, Additional file 2) indicated eight carbons in the range of $\delta 128-140$, these signals were characteristic of $\mathrm{C}=\mathrm{C}$ system present in the compounds. Another carbon signal at $\delta 214$ indicated a ketone unit in the structure. Two carbons at $\delta 63.8$ and 74.6 were assigned as $\mathrm{CH}-\mathrm{OH}$ and $\mathrm{CH}_{2}-\mathrm{OH}$ with the help of HSQC (Additional file 3) and DEPT-135 spectra (Additional file 4) of the compound NFAT-133.

The ${ }^{1} \mathrm{H}$ NMR (Additional file 5) and COSY spectra suggested the presence of trisubstituted benzene ring with coupled proton signal at $\delta 7.2(\mathrm{C}-5), 7.07(\mathrm{C}-7)$ and $7.05(\mathrm{C}-8)$. A proton signal at $\delta 2.3$ singlets was assigned as $\mathrm{Me}$ group at C-6 position. The olefinic protons at C- 


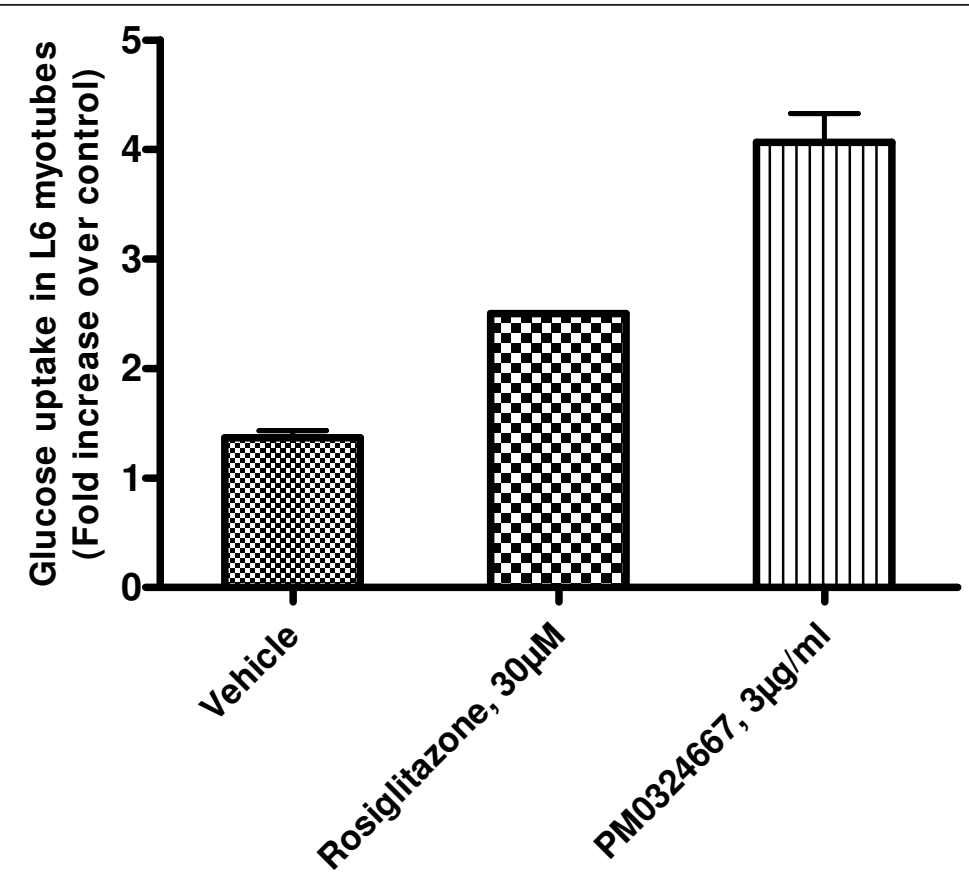

Figure 2 Effect of the ethyl acetate extract of Streptomyces strain PM034667 on glucose uptake in differentiated L6 myotubes sensitized to insulin.

3, $\mathrm{C}-4$ and the only $\mathrm{CH}_{2}$ unit at $\mathrm{C}-1$ were well correlated in COSY spectrum.

The other proton signals were also assigned to their respective carbons with the help of HSQC, COSY and DEPT spectra of the compound. The complete interpretation of data was in full agreement with the reported values of the compound NFAT-133 (Figure 3) (Burres et al. 1995; Qureshi et al. 2001).

\section{Effect of NFAT-133 treatment in vitro}

Bioactivity guided isolation of the active compounds resulted in isolation of the compound NFAT-133. This compound has been previously isolated from a Streptomyces strain AB 2184C-502 and derived its name

Table 1 Effect of the ethyl acetate extract (111/27/E.A) of Streptomyces strain PM034667 and fractions 1111/38/1, 2 and 3 on glucose uptake in differentiated L6 myotubes

\begin{tabular}{|c|c|c|}
\hline Sample \# & $\begin{array}{l}\text { Glucose uptake in L6 myotubes* } \\
\text { (Fold increase over control at } 3 \\
\mu \mathrm{g} / \mathrm{ml} \text { ) }\end{array}$ & Inference \\
\hline EA-crude & 2.5 & Active \\
\hline Fraction-1 & 2.4 & Active \\
\hline Fraction-2 & 1.4 & $\begin{array}{l}\text { Not } \\
\text { active }\end{array}$ \\
\hline Fraction-3 & 1.5 & $\begin{array}{l}\text { Not } \\
\text { active }\end{array}$ \\
\hline $\begin{array}{l}\text { Rosiglitazone (4 } \mu \mathrm{g} / \\
\mathrm{ml} \text { ) }\end{array}$ & 1.8 & Active \\
\hline
\end{tabular}

NFAT-133 due to its ability to inhibit the activation of the transcription factor - NFAT in Jurkat T-cells and block proliferation of splenocytes derived from Balb/c and C57BL/6 mice in vitro (Burres et al.1995). Herewith we report its effect on glucose uptake in differentiated skeletal muscle cells. NFAT-133 induces increased glucose uptake in $\mathrm{L} 6$ myotubes in presence of insulin $\left(\mathrm{EC}_{50}\right.$ $=6.3 \pm 1.8 \mu \mathrm{M})$. This effect is comparable to the effect of rosiglitazone $\left(\mathrm{EC}_{50}=6.9 \pm 1.8 \mu \mathrm{M}\right)$ under similar experimental conditions (Figure 4). However, unlike rosiglitazone, NFAT-133 does not significantly affect PPAR- $\gamma$ activity (Table 3 ). Rosiglitazone is a full agonist of PPAR- $\gamma$ at $1 \mu \mathrm{M}$. Whereas NFAT-133 even at concentrations as high as $100 \mu \mathrm{M}$, does not induce PPAR- $\gamma$ activity, indicating that NFAT-133 stimulates glucose uptake via mechanisms distinct from that of rosiglitazone.

\section{Effect of NFAT-133 treatment in vivo}

Rosiglitazone treatment induces glucose uptake in insulin-resistant rat skeletal muscle cells by activating PPAR $-\gamma$ and by increasing the resident AMPK $\alpha 2$ activity of these cells. Similarly, troglitazone a PPAR- $\gamma$ dual agonist increases glucose uptake by inducing GLUT4 translocation in L6 skeletal muscles (Lessard et al. 2006; Yonemitsu et al. 2001). However, these compounds are PPAR- $\gamma$ agonists, and have several side-effects that cause increased body weight and hepaptoxicity on chronic exposure. Since NFAT-133 increases glucose uptake in 
Table 2 NMR assignment for NFAT-133 in $\mathrm{CDCl}_{3}$

\begin{tabular}{|c|c|c|c|c|}
\hline Carbon\# & ${ }^{13} \mathrm{C}$ NMR & ${ }^{1} \mathrm{H}$ NMR & Reported ${ }^{13} \mathrm{C}$ NMR & Reported ${ }^{1} \mathrm{H}$ NMR \\
\hline 1 & $63.8\left(\mathrm{CH}_{2}\right)$ & 4.3 , bs & $63.7\left(\mathrm{CH}_{2}\right)$ & $4.2, \mathrm{dd}$ \\
\hline 2 & $131.6(\mathrm{CH})$ & $6.2, \mathrm{dt}$ & $132.8(\mathrm{CH})$ & $6.1, \mathrm{dt}$ \\
\hline 3 & $128.9(\mathrm{CH})$ & $6.9, d$ & $129.3(\mathrm{CH})$ & $6.9 \mathrm{dt}$ \\
\hline 4 & $136.1(\mathrm{Q})$ & - & 137.2(Q) & - \\
\hline 5 & $128.0(\mathrm{CH})$ & 7.2, Overlap & 128.6(CH) & $7.2, d$ \\
\hline 6 & $135.9(Q)$ & - & 137.0(Q) & - \\
\hline 7 & $128.7(\mathrm{CH})$ & $7.07, \mathrm{dd}$ & $129.7(\mathrm{CH})$ & $7.07 \mathrm{dd}$ \\
\hline 8 & $126.6(\mathrm{CH})$ & $7.05, \mathrm{dd}$ & $128.0(\mathrm{CH})$ & $7.05, d$ \\
\hline 9 & $138.6(Q)$ & - & $140.2(Q)$ & - \\
\hline 10 & $37.3(\mathrm{CH})$ & 3.1, m & $39.8(\mathrm{CH})$ & $3.08, \mathrm{dq}$ \\
\hline 11 & $74.6(\mathrm{CH})$ & 4.1, m & $76.6(\mathrm{CH})$ & $4.2, \mathrm{dd}$ \\
\hline 12 & $48.5(\mathrm{CH})$ & $2.5, \mathrm{~m}$ & $51.2(\mathrm{CH})$ & $2.3, \mathrm{qd}$ \\
\hline 13 & $214(Q)$ & - & $214.2(Q)$ & - \\
\hline 14 & $29.3\left(\mathrm{CH}_{3}\right)$ & $2.1, \mathrm{~s}$ & $28.4\left(\mathrm{CH}_{3}\right)$ & $2.05, \mathrm{~s}$ \\
\hline 15 & $21.1\left(\mathrm{CH}_{3}\right)$ & $2.3, \mathrm{~s}$ & $21.0\left(\mathrm{CH}_{3}\right)$ & $2.2, \mathrm{~s}$ \\
\hline 16 & $17.5\left(\mathrm{CH}_{3}\right)$ & $1.3, d$ & $19.2\left(\mathrm{CH}_{3}\right)$ & $1.2, d$ \\
\hline 17 & $10.8\left(\mathrm{CH}_{3}\right)$ & $1.09, \mathrm{~d}$ & $9.7\left(\mathrm{CH}_{3}\right)$ & $0.9, d$ \\
\hline
\end{tabular}

The NMR data for NFAT-133

${ }^{1} \mathrm{H}$ NMR $\left(500 \mathrm{MHz}, \mathrm{CDCl}_{3}\right): \delta 7.26(1 \mathrm{H}$, overlap, H-5), $7.07(1 \mathrm{H}, \mathrm{d}, \mathrm{H}-7), 7.05(1 \mathrm{H}, \mathrm{d}, \mathrm{H}-8), 6.9(1 \mathrm{H}, \mathrm{d}, \mathrm{J}=15.5 \mathrm{~Hz}, \mathrm{H}-3), 6.2(1 \mathrm{H}, \mathrm{dt}, \mathrm{J}=15.5 \mathrm{~Hz}, \mathrm{H}-2), 4.37(2 \mathrm{H}, \mathrm{bs}, \mathrm{H}-1)$, $4.11(1 \mathrm{H}, \mathrm{bs}, \mathrm{H}-11), 3.12(1 \mathrm{H}, \mathrm{m}, \mathrm{H}-10), 2.52(1 \mathrm{H}, \mathrm{m}, \mathrm{H}-12), 2.35(3 \mathrm{H}, \mathrm{s}, \mathrm{H}-15), 2.14(3 \mathrm{H}, \mathrm{s}, \mathrm{H}-14), 1.34(3 \mathrm{H}, \mathrm{d}, \mathrm{J}=7.0 \mathrm{~Hz}, \mathrm{H}-16), 1.09(3 \mathrm{H}, \mathrm{d}, \mathrm{J}=7.0 \mathrm{~Hz}, \mathrm{H}-17)$,

${ }^{13} \mathrm{C} \mathrm{NMR}\left(75 \mathrm{MHz}, \mathrm{CDCl}_{3}\right): \delta 214(\mathrm{C}=\mathrm{O}), 138.6(\mathrm{C}, \mathrm{C}-9), 136.13(\mathrm{C}, \mathrm{C}-4), 135.9(\mathrm{C}, \mathrm{C}-6), 131.6(\mathrm{CH}, \mathrm{C}-2), 128.9(\mathrm{CH}, \mathrm{C}-3), 128.74(\mathrm{CH}, \mathrm{C}-7), 128.0(\mathrm{CH}, \mathrm{C}-5), 126.6(\mathrm{CH}$, $\mathrm{C}-8), 74.65(\mathrm{CH}, \mathrm{C}-11), 63.83\left(\mathrm{CH}_{2}, \mathrm{C}-1\right), 48.57(\mathrm{CH}, \mathrm{C}-12), 37.3(\mathrm{CH}, \mathrm{C}-10), 29.3\left(\mathrm{CH}_{3}, \mathrm{C}-14\right), 21.11\left(\mathrm{CH}_{3}, \mathrm{C}-15\right), 17.58\left(\mathrm{CH}_{3}, \mathrm{C}-16\right), 10.8\left(\mathrm{CH}_{3}, \mathrm{C}-17\right)$.

L6 myotubes and does not agonise PPAR- $\gamma$ receptors significantly, we decided to investigate its in vivo profile in diabetic animals. Prior to planning an efficacy study we determined the pharmacokinetic profile of NFAT133 (Figure 5, Table 4) using female $d b / d b$ mice with $n$ $=4$ per time point. NFAT-133 was found to have poor oral bioavailability. But, since the compound appeared to have a novel mechanism of action, we decided to explore its in vivo efficacy potential by attempting the intraperitoneal route of administration. NFAT-133 administered by the intraperitoneal route achieved plasma concentrations higher than the in vitro $\mathrm{EC}_{50}$ in skeletal muscles. The dose selected, was 20 times higher

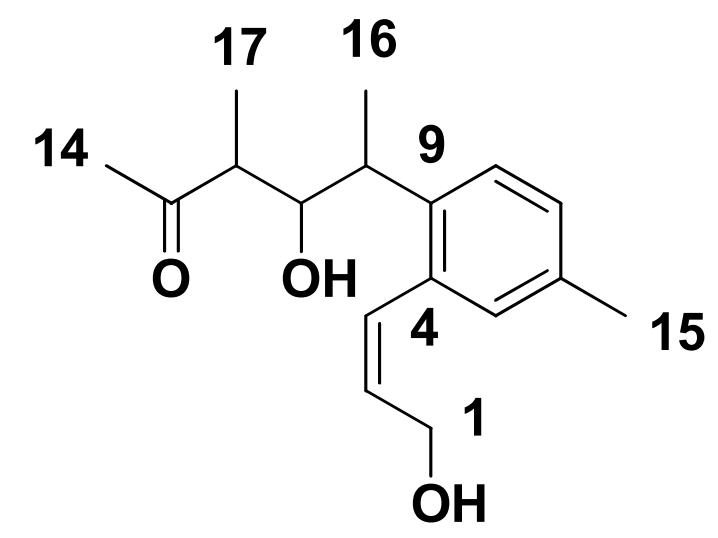

Figure 3 Structure of NFAT-133. than that of rosiglitazone on the basis of the pharmacokinetic profile of the compound, so as to have the sufficient exposure to show the pharmacological effect.

NFAT-133 showed a significant reduction in plasma glucose and plasma insulin levels as compared to vehicle treated animals. The decrease in plasma glucose and insulin in the NFAT-133 group was similar to that observed in rosiglitazone treated group (Figure 6). The liver weight of rosiglitazone treated animals was significantly increased as compared to vehicle treated group, (Table 5) $(2.3 \pm 0.1 \mathrm{~g}$ vs. $2.7 \pm 0.1 \mathrm{~g})$, while NFAT-133 had no effect on liver weight $(2.0 \pm$ $0.1 \mathrm{~g})$. In addition, rosiglitazone showed significant increase in body weight, which is the well known adverse effect of PPAR- $\gamma$ agonists. Our compound NFAT-133 showed significant reduction in body weight gain as compared to the vehicle treated animals (\% change in body wt: $6.02 \pm 0.64,14.63 \pm 0.85$ and $-1.08 \pm 1.21$ in vehicle, rosiglitazone and NFAT133, respectively). This is a beneficial effect over the compounds belonging to the class of PPAR- $\gamma$ agonists; e.g., rosiglitazone (Table 5).

\section{Discussion}

Streptomyces pactum was known to produce antitumor compounds like pactamycin (Bhuyan 1962), vasodilating secondary metabolite like actinopyrones A, B and C (Yano et al. 1986), NADH oxidase inhibitors such as piericidin class of compounds (Matsumoto et al. 1987), 


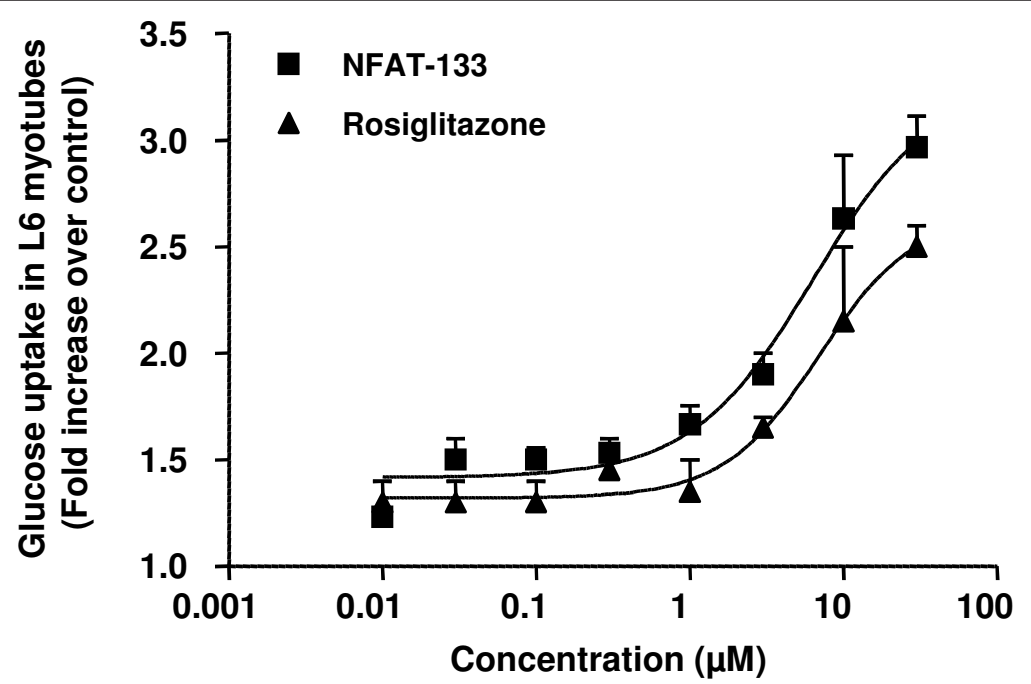

Figure 4 Dose dependent increase in glucose uptake activity in differentiated L6 mytubes sensitized with insulin and exposed to log dose concentrations of NFAT-133 (- - -) and rosiglitazone (-4-).

and polyetheric antibiotics such as lonomycin (Hamill et al. 1989). Similarly Streptomyces parvisporogenes has been reported to synthesize polyenic antifungal agent like Antibiotic PA 616 (Chas 1960) and pepstatin class of compounds which are pepsin inhibitors (Umezawa 1970). There has been no report of NFAT-133 or similar class of compounds isolated from strains of Streptomyces pactum or Streptomyces parvisporogenes to date.

Our screening program for new compounds has yielded the compound NFAT-133. NFAT-133 elicits a significant and dose dependent glucose uptake response in differentiated L6 cells. In skeletal muscles the glucose uptake is mediated by activation of the transporter molecule GLUT4 (Wijesekara et al. 2006). GLUT4 activation is controlled by regulatory proteins which activate either the AMPK or PI3K pathway. Several natural products have been earlier reported to elicit similar responses in L6 skeletal muscle cells. We have shown that the plant extracts Aegle marmelos and Syzygium cumini stimulate glucose uptake in skeletal muscle by augmenting the activity of the regulatory molecules; phosphatidyl inositol-3-kinase (PI3K), AMPK and GLUT-4 (Anandharajan et al. 2006). Ganoderma lucidum extract stimulates glucose uptake in L6

Table 3 Effect of NFAT-133 on PPAR- $\gamma$ activity in human PPAR- $\gamma$ receptor transfected CV1 cells

\begin{tabular}{ll}
\hline Compound & \% hPPAR- $\boldsymbol{\gamma}$ activation \\
\hline NFAT-133, $100 \mu \mathrm{M}^{*}$ & 9.0 \\
NFAT-133, 30 $\mu \mathrm{M}^{*}$ & 0.2 \\
Rosiglitazone, $1 \mu \mathrm{M}^{*}$ & 100 \\
\hline$* \mathrm{n}=3$ &
\end{tabular}

rat skeletal muscle cells by stimulating the activity of PI3K as well as a PI3K independent pathway which is controlled by the AMP activated protein kinase (Kamei et al. 2002; Jung et al. 2006; Cheng et al. 2006). It is possible that NFAT-133 may be mediating its effects through some of these pathways since the compound did not significantly activate PPAR- $\gamma$. PPAR $-\gamma$ is a major signaling molecule that is implicated in glucose uptake by skeletal muscle cells in vivo. However, activation of this receptor has several drawbacks. This has been noted especially in the case of thiazolidinediones which are very successful in reducing the clinical symptoms of diabetes. However, their major drawback is that they mediate their effects through activation of the PPAR- $\gamma$ family of nuclear receptors. The most significant side effects of this group of compounds include weight gain, hepatotoxicity and cardiovascular manifestations. The fact that our compound NFAT133 did not induce glucose uptake through activation of PPAR- $\gamma$ is significant. Hence, we evaluated the efficacy of the molecule in reducing systemic blood glucose levels in $d b / d b$ mice. Our data showed that NFAT-133 reduces systemic blood glucose levels. This was correlated with a simultaneous decrease in plasma insulin. Though actinomycetes produce few but prominent antidiabetic compounds, our report of NFAT-133 activity has revealed that further exploration of actinomycetes group will provide an avenue for discoveries leading to new medicines for diabetes. In conclusion, we found that NFAT-133, a natural product isolated from Streptomycetes, stimulates glucose uptake in L6 myotubes. This mechanism might explain its antihyperglycemic effects in diabetic animals. 

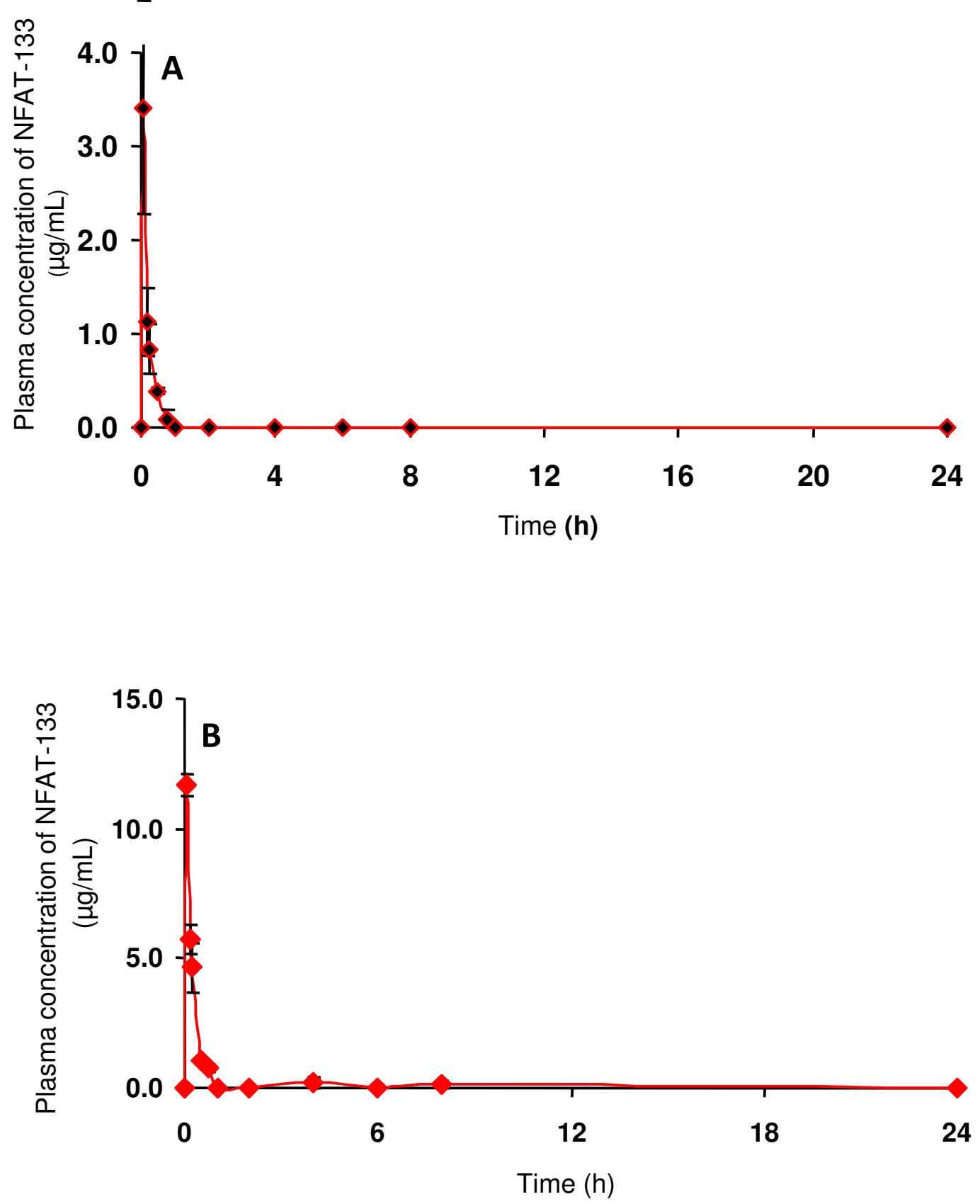

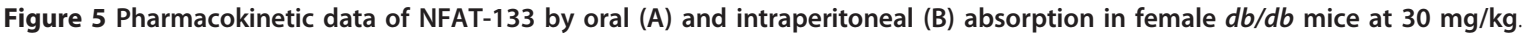

Table 4 Pharmacokinetic (PK) profile of NFAT-133 (30 $\mathrm{mg} / \mathrm{kg})$ administered orally and intraperitoneally in female $d b /$ db mice

\begin{tabular}{lll}
\hline PK & Oral & IP \\
\hline$T \max (\mathrm{h})$ & 0.08 & 0.08 \\
\hline $\mathrm{C} \max (\mu \mathrm{g} / \mathrm{ml})$ & 3.41 & 11.653 \\
\hline $\mathrm{C} \max (\mu \mathrm{M})$ & 12.34 & 42.221 \\
\hline AUC last & 0.63 & 3.217 \\
\hline AUC 0-infinity & 0.65 & 3.553 \\
\hline T1/2 (h) & 0.16 & 1.86
\end{tabular}

IP: intraperitoneal, $T_{\max }(h)$ : Time to maximum observed plasma concentration, $C_{\text {max }}$ : Maximum observed plasma concentration, AUC last: Area under the concentration-time curve from time 0 to the time of last observed concentration, $A \cup C_{0-\text { infinity: }}$ Area under the concentration-time curve from time 0 to infinity, and $\mathrm{T}_{1 / 2}$ : Terminal half-life. 


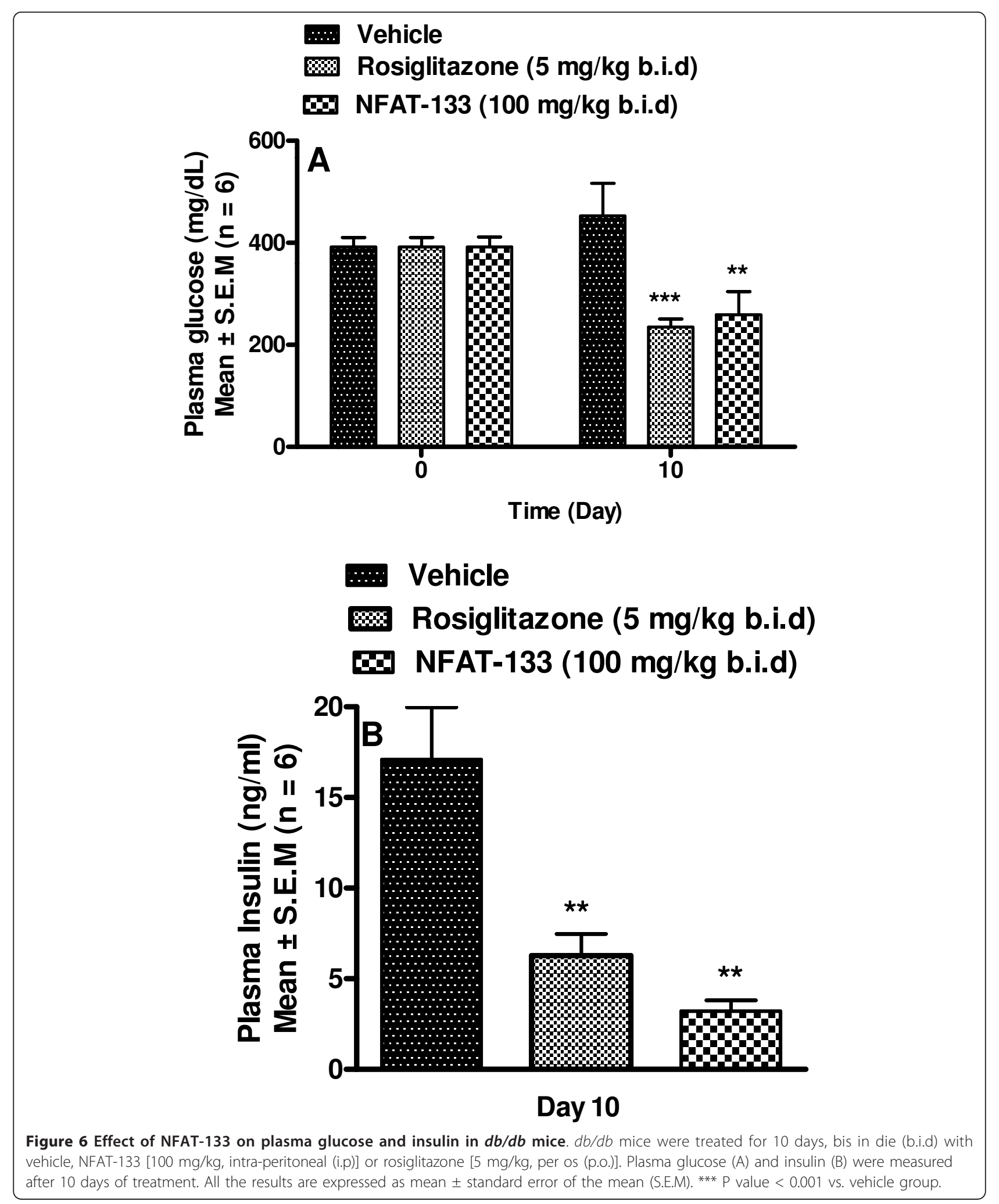


Table 5 Effect of NFAT-133 and rosiglitazone on the body weight and liver weight in response to treatment in $d b / d b$ mice

\begin{tabular}{lll}
\hline Group & \% Change in body weight & \% Change in liver weight \\
\hline Vehicle & $6.0 \pm 0.6$ & $2.3 \pm 0.1$ \\
\hline Rosiglitazone, $5 \mathrm{mg} / \mathrm{kg}$, po & $14.6 \pm 0.8^{* *}$ & $2.6 \pm 0.1^{*}$ \\
\hline NFAT-133, $100 \mathrm{mg} / \mathrm{kg}$, ip & $-1.1 \pm 1.2^{* *}$ & $2.0 \pm 0.1^{*}$ \\
\hline
\end{tabular}

Mice were treated for 10 days, bis in die (b.i.d) with vehicle, NFAT-133 [100 mg/kg, intra-peritoneal (i.p)] or rosiglitazone [5 mg/kg, per os (p.o.)]. The percent change in liver and bidy weight were measured after 10 days of treatment. All the results were expressed as Mean \pm S.E.M. $(n=10)$. ${ }^{*} p<0.01$ and ${ }^{*} p<0.05$ vs. day 0 .

\section{Conclusions}

Antihyperglycemic effects of the Streptomycetes compound NFAT-133 has been revealed by in vitro and animal studies.

\section{Additional material}

\section{Additional file 1: ESI-MS of the compound NFAT-133. The}

chromatogram represents the molecular mass of the isolated compound NFAT-133 from the Streptomyces strain PM0324667. The sample ID for the compound was: 1111-41-1.

Additional file 2: ${ }^{13} \mathrm{C}$ NMR of the compound NFAT-133. The chromatogram represents the ${ }^{13} \mathrm{C}$ NMR of the isolated compound NFAT133 from the Streptomyces strain PM0324667. The sample ID for the compound was: 1111-41-1.

Additional file $3:{ }^{13} \mathrm{C}$ HSQC of the compound NFAT-133. The chromatogram represents the ${ }^{13} \mathrm{C}$ HSQC of the isolated compound NFAT133 from the Streptomyces strain PM0324667. The sample ID for the compound was: 1111-41-1.

Additional file 4: DEPT-135 of the compound NFAT-133. The chromatogram represents the DEPT-135 of the isolated compound NFAT133 from the Streptomyces strain PM0324667. The sample ID for the compound was: 1111-41-1.

Additional file 5: ${ }^{1} \mathrm{H}$ NMR of the compound NFAT-133. The chromatogram represents the ${ }^{1} H$ NMR of the isolated compound NFAT133 from the Streptomyces strain PM0324667. The sample ID for the compound was: 1111-41-1.

\section{Acknowledgements}

The authors are very grateful to Somesh Sharma (Managing Director, Piramal Life Sciences Limited), H. Sivaramkrishnan (President, Piramal Life Sciences Limited), and Arun Balakrishnan (Vice President, External Liaison and Screening, Piramal Life Sciences Limited) for the encouragement and approvals towards this work and the publication.

\section{Author details}

${ }^{1}$ Piramal Life Sciences Limited, 1-Nirlon Complex, Off Western Express Highway, Goregaon (East), Mumbai-400063, Maharashtra State, India ${ }^{2}$ Indian Institute of Integrative Medicine (IIIM), Canal Road, Jammu-180001, Jammu and Kashmir, India

\section{Authors' contributions}

Microbiology and fermentation: GBM, SDG, RRP, PVR, PT, In vitro screening and analysis: AAK, MKB, PP, CST, ASN, In vivo evaluation: KVN, AAD, UAB, NJD, LSD, AVD, Chemical isolation and structural elucidation: PDM, NVG, RAV

\section{Competing interests}

The authors declare that they have no competing interests.

Received: 4 November 2011 Accepted: 21 November 2011 Published: 21 November 2011

\section{References}

Anandharajan $\mathrm{R}$, Jaiganesh S, Shankernarayanan NP, Viswakarma RA, Balakrishnan A (2006) In vitro glucose uptake activity of Aegeles marmelos and Syzygium cumini by activation of Glut-4, PI3 kinase and PPAR- $\gamma$ in L6 myotubes. Phytomedicine 13:434-441. doi:10.1016/j.phymed.2005.03.008.

Arun DS, Jaspreet S (2005) A nonenzymatic method to isolate genomic DNA from bacteria and actinomycete. Analytical Biochemistry 337(2):354-356. doi:10.1016/j.ab.2004.11.029.

Bhuyan BK (1962) Pactamycin Production by Streptomyces pactum. Appl Microbiol 10(4):302-304

Burres NS, Premachandran U, Hoselton S, Cwik D, Hochlowski JE, Ye O Sunga GN, Karwowski JP, Jackson M, Whittern DN, Mcalpine JB (1995) Simple aromatics identified with a NFAT-lacZ transcription assay for the detection of immunosuppressants. J Antibiot 48(5):380-386

Chas. Pfizer and Co (1960) Antibiotic designated compound 616 from streptomyces parvisporogenes. Inc. British Patent 832391

Cheng Z, Pang T, Gu M, Gao AH, Xie CM, Li JH, Nan FHL (2006) Berberinestimulated glucose uptake in L6 myotubes involves both AMPK and p38 MAPK. Biochim Biophys Acta 1760(11):1682-1689. doi:10.1016/j. bbagen.2006.09.007

De Melo EB, Gomes ADS, Carvalho I (2006) $\alpha$ - and $\beta$-Glucosidase inhibitors: chemical structure and biological activity. Tetrahedron 62(44):10277-10302. doi:10.1016/j.tet.2006.08.055.

Hamill RL, Yao RC (1989) Process for producing antibiotic A80438. U.S. patent $4,830,967$

Huang C, Somwar R, Patel N, Niu W, Torok D, Klip A (2002) Sustained Exposure of L6 Myotubes to High Glucose and Insulin Decreases Insulin-Stimulated GLUT4 Translocation but Upregulates GLUT4 Activity. Diabetes 51:2090-2098. doi:10.2337/diabetes.51.7.2090.

Jung KH, Ha E, Kim MJ, Uhm YK, Kim HK, Hong SJ, Chung JH, Yim SV (2006) Ganoderma lucidum extract stimulates glucose uptake in L6 rat skeletal muscle cells. Acta Biochimica Polonica 53(3):597-601

Kameda Y, Asano N, Yoshikawa M, Matsui K (1980) Valienamine as an aglucosidase inhibitor. J Antibiot 33(12):1575-1576

Kameda Y, Asano N, Yoshikawa M, Takeuchi M, Yamaguchi T, Matsui K, Horii S, Fukase H (1984) Vaholamine, a new a-glucosidase inhibiting aminocyclitol. produced by Streptomyces hygroscopicus. J Antibiot 7(11):1301-1307

Kamei R, Kitagawa Y, Kadokura M, Hattori F, Hazeki O, Ebina Y, Nishihara T, Oikawa S (2002) Shikonin Stimulates Glucose Uptake in 3T3-L1 Adipocytes via an Insulin-Independent Tyrosine Kinase Pathway. Biochem Biophys Res Commun 292:642-651. doi:10.1006/bbrc.2002.6714.

Kulkarni-Almeida AA, Suthar A, Goswami H, Vishwakarma R, Chauhan VS, Balakrishnan A, Sharma S (2008) Novel leads from Heliotropium ovalifolium, 4,7,8-trimethoxy-naphthalene-2-carboxylic acidand6-hydroxy-5,7-dimethoxynaphthalene-2-carbaldehyde showspecific IL-6inhibitoryactivityinTHP-1 cells and primary human monocytes. Phytomedicine 15:1079-1086. doi:10.1016/j. phymed.2008.04.013.

Lessard SJ, Chen ZP, Watt MJ, Hashem M, Reid JJ, Febbraio MA, Kemp BE, Hawley JA (2006) Chronic rosiglitazone treatment restores AMPK 2 activity in insulin-resistant rat skeletal muscle. Am J Physiol Endocrinol Metab 290: E251-E257

Mahmud T (2003) The $C_{7} \mathrm{~N}$ aminocyclitol family of natural products. Nat Prod Rep 20(1):137-166. doi:10.1039/b205561a.

Mark M, Grell W (1997) Hypoglycaemic effects of the novel antidiabetic agent repaglinide in rats and dogs. Br J Pharmacol 121:1597-1604. doi:10.1038/sj. bjp.0701307.

Matsumoto M, Mogi K, Nagaoka K, Ishizeki S, Kawahara RN (1987) New piericidin glucosides, glucopiericidins A and B. J Antibiot (Tokyo) 40(2):149-56 
Norman P (2010) Diabetes Pipeline: Intense Activity to Meet Unmet Need Report- Overview. Cambridge Healthtech Institute, Massachusetts (USA)

Quinn RJ, Almeida LPDe, Guymer G, Hooper JNA (2002) Australian biodiversity via its plants and marine organisms - A high-throughput screening approach to drug discovery. Pure Applied Chemistry 74(4):519-526. doi:10.1351/ pac200274040519.

Qureshi A, Mauger JB, Cano RJ, Galazzo JL, Lee MD (2001) MF-EA-705a and MF EA - 705b, new metabolites from microbial fermentation of Streptomyces sp. J Antibiot 54(12):1100-1103

Schmidit DD, Frommer W, Junge B, Muller L, Wingender W, Truscheit E, Schafer D (1977) a-Glucosidase inhibitors. Naturwissenschaften 64(10):535-536. doi:10.1007/BF00483561.

Truscheit E, Frommer W, Junge B, Muller L, Schmidt DD, Wingender W (1981) Chemistry and Biochemistry of Microbial -Glucosidase Inhibitors. Angew Chem Int Ed Engl 20:744-761. doi:10.1002/anie.198107441.

Umezawa H, Aoyagi T, Morishima H, Matsuzaki M, Hamada M, Takeuchi T (1970) Pepstatin, a new pepsin inhibitor produced by agtinomygetes. J Antibiot (Tokyo) 23:259-262

Wijesekara N, Thong FSL, Antonescu CN, Klip A (2006) Diverse Signals Regulate Glucose Uptake into Skeletal Muscle. Can J Diabetes 30(1):80-88

Xu H, Yang J, Bai L, Deng Z, Mahmud T (2009) Genetically engineered production of 1,1'-bis-valienamine and validienamycin in Streptomyces hygroscopicus and their conversion to valienamine. Appl Microbiol Biotechnol 81(5):895-902. doi:10.1007/s00253-008-1711-z.

Yano K, Yokoi K, Sato J, Oono J, Kouda T, Ogawa Y, Nakashima T (1986) Pactamycin Production by Streptomyces pactum. J Antibiot 34(1):32-37

Yokose K, Ogawa K, Sano T, Watanabe K, Maruyama HB, Suhara Y (1983) New aamylase inhibitor, Trestatins I. Isolation, characterization and biological activities of Trestatins A, B and C. J Antibiot 36(9):1157-1165

Yokose K, Ogawa M, Ogawa K (1984) New a-amylase inhibitor, Trestatins III. Structure determination of New Trestatin Components Ro 09-0766, Ro 090767 and Ro 09-0768. J Antibiot 37(2):182-186

Yonemitsu S, Nishimura H, Shintani M, Inoue R, Yamamoto $Y$, Masuzaki H, Ogawa Y, Hosoda K, Inoue G, Hayashi T, Nakao K (2001) Troglitazone Induces GLUT4 Translocation in L6 Myotubes. Diabetes 50:1093-1101. doi:10.2337/ diabetes.50.5.1093.

doi:10.1186/2191-0855-1-42

Cite this article as: Kulkarni-Almeida et al:: Fermentation, Isolation,

Structure, and antidiabetic activity of NFAT-133 produced by

Streptomyces strain PM0324667. AMB Express 2011 1:42

\section{Submit your manuscript to a SpringerOpen ${ }^{\circ}$ journal and benefit from:}

- Convenient online submission

- Rigorous peer review

- Immediate publication on acceptance

- Open access: articles freely available online

- High visibility within the field

- Retaining the copyright to your article

Submit your next manuscript at $>$ springeropen.com 